\title{
TEATRO DE FANTOCHES NA EDUCAÇÃO INFANTIL
}

Vagner de Souza Vargas ${ }^{1}$

vagnervarg@yahoo.com.br

Denise Marcos Bussoletti2

denisebussoletti@gmail.com

\section{INTRODUÇÃO}

O teatro de formas animadas está presente desde os primórdios da humanidade, quando os homens utilizavam objetos e partes do seu corpo para criarem formas através das sombras projetadas em alguma superfície e ali contarem histórias para os demais. Além disso, 0 teatro de bonecos sempre esteve presente nas manifestações culturais de vários povos desde à antiguidade, sendo impossível precisar a data do seu surgimento (CARLSON, 1997; BERTHOLD, 2011).

O teatro de bonecos vem sendo utilizado como estratégia para diversas metodologias pedagógicas no ensino fundamental (BIARNÉS, 1998; GUERRA, 2004; NEVES, 2004). A sua adaptação para o contexto escolar, assim como para cada faixa etária em que 0 teatro de bonecos, fantoches e dedoches serão utilizados, deve ser feita com cautela para que eles funcionem como aproximação dos alunos aos conteúdos que serão abordados em sala de aula (MACHADO, 1970; BRITTO, 1982; GUERRA, 2004; SILVA, 2011).

Abordagens de ensino que envolvem o teatro de formas animadas devem estar atentas à análise reflexiva relacionada à forma lúdica de ensinar utilizando fantoches e suas perspectivas como artefato educativo no ensino infantil, tanto no que se refere a educar, provocar, instigar

\footnotetext{
1 Ator, Mestre em Ciências da Saúde, Licenciado em Teatro.

2 Doutora em Psicologia, Professora do Programa de Pós-Graduação em Educação. Faculdade de Educação. Universidade Federal de Pelotas. Diretora da Editora e Gráfica Universitária UFPEL. 
questionamentos, ensinar conteúdos, quanto ao ensino da arte e o desenvolvimento da criança com sua mente criadora em personificação e dramatização (SILVA, 2011). Nas brincadeiras do faz-de-conta, a criança atribui características e vida a objetos, criando situações imaginárias e realizando dramatizações de acordo com seus significados culturais (SILVA, 2011; SLADE, 1978; SPOLIN, 2003).

No texto a seguir, serão apresentados alguns aspectos observados durante as atividades realizadas nos meses de setembro à novembro de 2011, em uma escola estadual de ensino fundamental, na cidade de Pelotas/RS, durante as aulas de teatro para os alunos do primeiro ano da educação infantil. Todas as aulas de teatro foram ministradas por dois alunos do sétimo semestre do Curso de Teatro - Licenciatura, da Universidade Federal de Pelotas (UFPEL).

\section{QUANDO O TEATRO ENCONTRA A ESCOLA}

Logo no primeiro dia de aula, constatamos que os alunos não haviam tido contato com nenhuma obra teatral, nem tão pouco possuíam referenciais sobre a linguagem teatral. Os únicos referenciais que essas crianças referiam ter, estavam ligados à linguagem televisiva. Desse modo, decidimos que, durante o período de atividades, levaríamos a turma para assistirem algum espetáculo de teatro, para terem um primeiro contato com a linguagem teatral. Esse fato nos possibilitou trabalhar a recepção teatral com essa turma, já preparando-as não somente para assistirem a uma peça de teatro específica, mas para irem ao teatro sempre que tiverem oportunidade.

Como os alunos desconheciam o evento teatral, durante as aulas, começamos trabalhando pequenas noções de jogo, em que eles precisariam aprender a escutar o próximo, para também serem escutados e aí estabelecerem uma relação. Todas as atividades já estavam sendo direcionadas para eles compreenderem a relação entre a pessoa que apresenta algo e 0 espectador. Nesse sentido, os exercícios com fantoches permitiram essa constatação de maneira mais evidente. Durante as apresentações para os colegas em sala de aula, 
observávamos que as crianças sentiam muita vontade de se aproximarem do seu "objeto de desejo" e cada vez mais ficarem próximas aos colegas que estavam apresentando.

O ensino de teatro na educação infantil ainda é uma área a ser estabelecida e as atividades precisam ser adaptadas a essa faixa etária. Nesse sentido, acreditamos que a opção de trabalharmos com fantoches foi um acerto, uma vez que, paulatinamente, as crianças foram aprendendo que podiam criar o seu próprio boneco e imaginar histórias que se relacionariam com as outras criadas pelos outros colegas para os seus fantoches. Além disso, essa noção de jogo por meio dos fantoches funcionou muito bem para estimular-lhes a percepção de que maneira se desenvolvia a relação entre aquele que apresenta e aquele que assiste.

Por meio das atividades com fantoches, pudemos trabalhar noções de recepção teatral e demais aspectos técnicos do fazer teatral, de maneira suave e lúdica. Ao longo das aulas, percebemos que essas crianças não conseguiam se manter focadas em uma mesma atividade por mais de 5 minutos, o que nos fazia mudar de exercícios constantemente, dando mais dinâmica às aulas. Contudo, já nas últimas aulas, observamos que os alunos permaneciam concentrados numa mesma atividade por mais tempo.

Um fato muito interessante que merece ser destacado, ocorreu quando, pela primeira vez, levamos um pano preto para servir de cortina, onde os alunos deveriam ficar escondidos para apenas levantarem seus fantoches e apresentarem-nos à plateia dos colegas que estava do outro lado. Durante esse exercício, as crianças ficavam fascinadas de conversarem com 0 fantoche, porém todas iam espiar atrás do pano, quem é que estava ali, ou se o corpo do fantoche tinha mais alguma parte escondida sob o pano. Inclusive, as duplas ou trios que estavam apresentando, também queriam ir para a frente do pano, junto à plateia, para verem os fantoches conversarem.

Outra experiência interessante, se refere aos exercícios de respiração, articulação e técnica vocal que aplicamos nessa turma. Por se tratar de crianças com tão pouca idade, tivemos que adaptar os exercícios para essa faixa etária. Para nossa surpresa, esses eram os exercícios que a turma mais gostava, permanecia concentrada e fazia todas atividades muito concentrada. Com isso, conseguimos observar que as crianças não respiravam usando a distensão máxima diafragmática e que a dislalia, apresentada por alguns, era própria da idade e 
não decorrente de algum problema motor ou articular. Esse tipo de experiência também têm sido relatado por outros autores (PENTEADO, 2007).

Como necessitam se fazer serem ouvidas e chamarem a atenção, essas crianças costumavam gritar para se comunicarem em sala de aula. No entanto, observamos que, durante os exercícios de técnica vocal, elas conseguiam deixar o som vibrar em alguns ressonadores faciais, o que já lhes permitia uma proteção a quaisquer danos que porventura aconteceriam as suas pregas vocais, quando fossem se comunicar num tom de voz mais elevado.

Por outro lado, observamos que as cantigas de roda e os jogos de regras seriam melhor aproveitados se fossem praticados em um espaço físico maior. No dia em que levamos as crianças para participarem de uma atividade conjuntamente ao elenco do espetáculo Eu Chovo, Tu Choves, Ele Chove, escrito por Sylvia Orthof, observamos que as crianças fizeram esses mesmos exercícios, porém num salão maior e que a atividade foi muito mais prazerosa e divertida.

As duas oportunidades que tivemos de levar uma peça de teatro para nossos alunos assistirem foram muito válidas. As crianças mantiveram-se muito atentas durante as apresentações e compreenderam todas as temáticas discutidas nos textos dos espetáculos. Além disso, como eles tiveram a oportunidade de observar como o elenco de um espetáculo se preparava para realizar uma apresentação, aproveitaram para conhecer como se processa 0 fazer teatral.

Apesar de terem participado das atividades que antecediam ao espetáculo, na hora da apresentação, as crianças desfrutaram da apresentação da mesma forma. Porém, agora, com um olhar mais apurado, já conhecendo algumas atividades que se desenvolvem antes do evento teatral. Além disso, o fato das crianças terem tido a oportunidade de colocarem os figurinos, elementos de cena e brincarem com as maquiagens, ajudou a estabelecer outra perspectiva de relação com o seu imaginário, uma vez que, ao colocarem alguns desses elementos, eles brincavam dizendo que agora eram tal ou qual personagem, criando situações e etc... 


\section{AS DIFICULDADES DE ADAPTAÇÃO DAS ESCOLAS PARA O ENSINO DE TEATRO}

Com uma média de idade de 6 anos, as 22 crianças da turma participavam das atividades propostas pelos professores de teatro em uma sala de aula muito pequena, com janelas sem grades e ventilador de teto estragado. Em função da pouca idade das crianças, não era possível abrir as janelas com o intuito de termos uma circulação de ar no interior da sala, visto que havia o risco de ocorrer algum acidente. Além disso, as aulas de teatro, segundo recomendações da coordenação pedagógica, deviam ser dadas com as portas fechadas para que 0 barulho das atividades não atrapalhasse aos professores que estavam dando aula nas salas ao lado.

Tendo em vista a inexistência de uma sala de aula apropriada para atividades de teatro nessa escola, as aulas de teatro ocorriam na sala de aula regular, porém a movimentação das cadeiras e classes incomodava aos professores das salas de aula que ficavam próximas. Por esse motivo, as aulas de teatro começaram a ser dadas na sala de leitura, uma sala menor que a outra, contendo algumas almofadas e um tapete. Conforme as crianças se movimentavam no tapete e nas almofadas, levantava muita poeira. Como não havia circulação de ar, a sala quente e empoeirada não oferecia um ambiente saudável para a execução das atividades.

Apesar disso, as aulas foram dadas nesse local. Devido ao espaço físico reduzido, as crianças, inevitavelmente, acabavam esbarrando umas nas outras durante as atividades propostas. Esse fato acabou se tornando um problema, uma vez que essas crianças reagiam de maneira muito agressiva, quando um colega se aproximava. Observamos que esse comportamento agressivo se dava em ambos os sexos e que, se os professores não interviessem, algum aluno poderia sair muito machucado. Um fato positivo para essa situação foi que as aulas eram dadas por dois professores, o que facilitava o controle, já que eram muitas crianças para um só professor. 
A escola conta com um pátio e uma praça para atividades lúdicas. Entretanto, não era possível utilizar esses espaços para nenhuma atividade teatral, pois, segundo a direção da escola, as crianças fariam muito barulho, o que viria a atrapalhar as outras aulas da escola. Diversas vezes, as crianças solicitavam que queriam brincar no pátio ou na pracinha. Mas, não era possível levá-las a esses espaços. No entanto, compensamos essas vontades realizando outras atividades adaptadas ao espaço que dispúnhamos.

\section{UMA DIFÍCIL REALIDADE ONDE O TEATRO PODE COLABORAR ESTREITANDO RELAÇÕES}

No primeiro dia de aula, percebemos que haviam dois alunos com algum tipo de característica que necessitaria de uma atenção diferenciada. Após essa observação, fomos conversar com a coordenação da escola com o objetivo de obtermos maiores informações sobre essas crianças. Nesse momento, fomos informados que a escola já havia percebido que esses alunos apresentavam características diferenciadas. Entretanto, não sabiam qual o diagnóstico dessas crianças.

Acreditamos que, quando há um aluno que apresente alguma característica que necessite de atenção especial, a escola deveria fornecer todas essas informações aos estagiários de cursos de licenciatura antes mesmo deles assumirem a turma. Apesar disso, não tivemos nenhum problema em lidar com esses dois alunos. Muito pelo contrário, essas crianças conseguiram desenvolver todas as atividades que propúnhamos. Além disso, se concentravam nos exercícios e demonstravam uma disciplina maior que os demais alunos.

Inclusive, as coordenadoras pedagógicas da escola acreditam que um desses meninos apresente algum tipo de autismo, porém ainda sem um diagnóstico conclusivo. Nesse sentido, fomos informados que ele não se comunicava com as demais pessoas. Notícia essa que recebemos com surpresa, pois, desde o primeiro contato, esse aluno sempre se expressou muito bem, com um vocabulário e concordância verbal superior aos demais colegas. Ao longo do período em que estivemos ministrando as aulas de teatro para essa turma, observamos que 
esse menino se divertia muito com as atividades propostas, se concentrava nos exercícios e sempre se propunha ao jogo.

Todavia, observamos que ele possuía o rótulo de "o doente" para os demais coleguinhas e que esse era o mote para os alunos o provocarem, deixarem-no agitado e agredirem-no fisicamente. No entanto, como éramos dois professores dentro da sala de aula, conseguimos observar que os outros alunos o agrediam, para logo em seguida dizerem que ele era quem agredia aos colegas. O rótulo recebido por esse aluno funcionava como desculpa para os colegas praticarem o bullying contra ele. Mesmo em se tratando de crianças com tão pouca idade, observamos que elas provocavam esse colega para que ele se descontrolasse e chamasse a atenção quando estivesse agredindo alguém ou gritando.

Pelo menos nas aulas de teatro esse quadro foi mudando, ao passo que, nas últimas aulas já não observávamos esse tipo de comportamento dos colegas em relação ao menino taxado como "o diferente". O outro menino que apresentava um comportamento cognitivo inferior a sua idade cronológica, sempre expressava uma carência afetiva muito grande. Em função disso, ele preferia ficar a aula inteira de mãos dadas com um dos professores, ou pedindo carinho. Como ele estava sempre de mãos dadas com o professor, nunca observamos nenhum tipo de provocação dos colegas em relação a ele.

Apesar desses dois meninos apresentarem características diferenciadas em relação aos demais colegas, essas peculiaridades não os impediam de realizar os exercícios das aulas de teatro. Muito pelo contrário, o teatro funcionou como um meio de estabelecer a comunicação e integração deles com o resto da turma. As atividades lúdicas e o estímulo ao imaginário do universo teatral criaram um elo diferenciado das propostas pedagógicas que até então eles haviam vivenciado. Um dos aspectos que nos permitiu essa evidenciação, se refere ao fato do menino que, até então, não conversava com ninguém no ambiente escolar, passou a se comunicar e a participar ativamente das atividades das aulas de teatro, principalmente, quando produzia os seus próprios fantoches e criava histórias em diálogo com os fantoches dos outros colegas.

A experiência realizada com essa turma obteve resultados positivos. Entretanto, expusemos esse fato, pois essa situação pode ser vivenciada por diversos professores ao se Revista "O Teatro Transcende" do Departamento de Artes - CCE da FURB - ISSN 2236-6644 - Blumenau, Vol. 18, № 1, p. 03 - 18, 2013 
depararem com alunos que necessitam de atenções diferenciadas em suas turmas. No entanto, ainda existe uma formação acadêmica muito frágil em relação ao preparo dos professores para enfrentarem diferentes contextos, atravessamentos e, inclusive, necessidades especiais de alunos que estarão integrados ao ensino regular. Independentemente da área específica em que o professor realizou o seu curso de licenciatura, o preparo para lidar com crianças com necessidades especiais deve estar presente nas disciplinas pedagógicas, uma vez que esta é uma realidade cada vez mais comum nos educandários.

Infelizmente, devido ao fato de muitos professores não terem tido essa abordagem ao longo da sua formação acadêmica em cursos de licenciatura, acabam tendo que enfrentar essa realidade, aprendendo no dia a dia a como manejar com as especificidades de cada caso. Não basta apenas à academia discutir teorias e reflexões sobre educação inclusiva e seus conceitos, há a necessidade de que os professores dos cursos de licenciatura preparem e instrumentalizem seus alunos com repertórios de práticas pedagógicas que abarquem as necessidades específicas que alguns de seus futuros alunos possam vir a necessitar.

No caso da experiência em questão, os resultados foram positivos. Todavia, eles foram alcançados tendo em vista mais a experiência profissional dos dois professores como artistas de teatro que já desenvolvem atividades em outros contextos há muitos anos, do que com subsídios obtidos na academia sobre como lidar com alunos com necessidades especiais nas aulas de teatro. $O$ teatro pode ser um adjuvante na inclusão social de pessoas com necessidades de atenção especial, porém os profissionais que irão trabalhar com esse público alvo devem ser preparados desde à graduação para lidarem com essas peculiaridades.

\section{CONSIDERAÇÕES FINAIS}

O ensino de teatro em escolas de educação infantil, ensino fundamental e médio ainda é uma novidade na cidade de Pelotas/RS. Na medida em que os alunos do Curso de Teatro Licenciatura, da Universidade Federal de Pelotas, realizam seus estágios curriculares, extra curriculares e atividades de ensino e extensão nas escolas do município, o ensino de teatro 
começa a ser reconhecido pelos profissionais responsáveis pela supervisão, direção e coordenação pedagógica desses educandários.

Apenas no ano de 2012, uma candidata licenciada foi aprovada em um concurso público para ministrar aulas de teatro em uma escola estadual. No recente concurso, realizado em 2013 , para o preenchimento de vagas no magistério público, realizado pelo governo do Estado do Rio Grande do Sul, mais três candidatos licenciados em teatro foram aprovados. Porém, ainda não foram empossados. Esse quadro ilustra a realidade do ensino de teatro nas escolas desse município. Uma situação que ainda caminha a passos lentos, inclusive para a inserção no mercado de trabalho dos profissionais licenciados em teatro, graduados anualmente pela Universidade Federal de Pelotas.

Apesar disso, nossas atividades foram adaptadas ao espaço e à realidade escolar que encontramos. No entanto, acreditamos que a comunidade escolar também deva ser preparada para receber quaisquer tipos de atividades teatrais, pois de nada adianta os profissionais licenciados em teatro estarem aptos para irem desempenhar suas atividades nos educandários, se não houver uma compreensão e boa vontade para saber que existem especificidades de área que necessitam ser respeitadas.

Como iremos trabalhar a expressão se nossos alunos não podem falar alto, correr, pular, gargalhar e etc? Acreditamos que as aulas de teatro devam se adaptar a quaisquer espaços. Entretanto, se existem locais mais adequados no ambiente escolar, deveríamos poder executar nossas atividades neles. Traçamos aqui um paralelo com a educação física, já que essa área consolidou o seu espaço no ambiente escolar e, atualmente, todas as escolas se adéquam às especificidades dessa área. Desse modo, acreditamos que esteja faltando conhecimento e força de vontade para que os profissionais que trabalham nesses educandários possibilitem que os profissionais de teatro desempenhem suas atividades nesses espaços de maneira adequada.

Além disso, acreditamos que os profissionais que trabalham nas escolas devam ser preparados para lidarem com as necessidades que um grupo de teatro tem, quando vai até à escola para realizar uma apresentação teatral. 0 que percebemos foi que havia um ideário, de que o teatro se proporia a ser ferramenta ao ensino de outras disciplinas, ou como coadjuvante ao preparo das crianças para apresentações em datas comemorativas da escola. Como não Revista "O Teatro Transcende" do Departamento de Artes - CCE da FURB - ISSN 2236-6644 - Blumenau, Vol. 18, № 1, p. 03 - 18, 2013 
existiam profissionais licenciados com formação em teatro trabalhando na maioria das escolas, não havia a manutenção de um trabalho que exemplificasse as especificidades do ensino de teatro.

Ademais, enquanto professores licenciados em teatro não ocupam as vagas para 0 ensino de teatro nas escolas pelotenses, os profissionais que se propõem a lidar com algum tipo de expressão performativa nas escolas, o fazem baseados em conhecimentos empíricos ou em "macetes" copiados de exercícios isolados em livros que proponham alguns exercícios para o ensino de teatro. A formação em teatro se faz necessária para que o empirismo não acabe gerando um imaginário equivocado da linguagem teatral e do próprio ensino e aprendizado em teatro.

No que se refere à metodologia de trabalho com fantoches, observamos nessas atividades que essa abordagem funcionou com os alunos da faixa etária com que estávamos trabalhando. Devido aos aspectos lúdicos da confecção e exercício prático com fantoches, eles podem ser utilizados como estratégia para abarcar diversos objetivos específicos da linguagem teatral, sobretudo na educação infantil.

\section{REFERÊNCIAS}

BERTHOLD, Margot. História Mundial do Teatro. São Paulo/SP: Perspectiva, 2011.

BIARNES, Jean. O ser e as letras: da voz à letra, um caminho que construímos todos. Rev. Fac. Educ., São Paulo, v. 24, n. 2, July 1998.

BRITTO, Teresa Teixeira; ZAKOVICS, Olalia de Brito. Teatro na Escola. Curitiba: Universidade Federal do Paraná, 1982.

CARLSON, Marvin. Teorias do teatro. São Paulo: UNESP, 1997. 
GUERRA, Raquel Angelo Torquemada; GUSMÃO, Christiane Rose de Castro; SIBRÃO, Edgard Ruiz. Teatro de Fantoches: Uma estratégia em educação ambiental. In: AZEITEIRO, U. M.,

PEREIRA, M. J., LEAL-FILHO, W., CAEIRO, S., BACELAR-NICOLAU, P., MORGADO, F. and GONÇALVES, F. (Eds). Global Trends on Environmental Education. Discursos, Universidade Aberta, Lisboa, $n^{0}$ especial: 361-375. 2004.

MACHADO, Maria Clara. Como Fazer Teatrinho de Bonecos. Rio de Janeiro: Agir, 1970.

NEVES, Andréa Collyer; HILLESHEIN, Araci Isaltina de Andrade; FACHIN, Gleisy Regina Bories. Utilização de caixas-estantes para 0 incentivo da leitura para alunos de $1^{\text {a }}$ à $4^{a}$ séries na escola municipal Henrique Veras. Revista Eletrônica de Extensão UFSC. 2004, vol.1, p.1-7.

PENTEADO, Regina Zanella; CAMARGO, Amanda Molina Dias de; RODRIGUES, Caroline Feleto; SILVA, Cristiane Rodrigues da; ROSSI, Daniele; COSTA E SILVA, Juliana Terra;

GONZALES, Patrícia; SILVA, Samanta Luisa de Souza Godoy. Distúrbios da Comunicação. 2007; vol.19, n.2, p.237-246.

SILVA, Maria de Nazaré Marques da. Teatro de fantoches: uma atividade cênica como estratégia para aprendizagem no ensino infantil. 2011. 38 f. Monografia (Licenciatura em Artes Cênicas)— Universidade de Brasília, Cruzeiro do Sul-AC, 2011.

SLADE, Peter. O Jogo Dramático Infantil. São Paulo: Summus, 1978.

SPOLIN, Viola. Improvisação Para o Teatro. Coleção Estudos. São Paulo: Perscpectiva, 2003. 